\section{B A Institute of \\ YK Business Administration \\ 六下 \\ Karachi \\ Leadership and Ideas for Tomorrow}

Business Review

Volume 13 Issue 2 July-December 2018

$1-3-2019$

\title{
Socioeconomic determinants of child mortality: Evidence from Pakistan Demographic and Health Survey
}

\author{
Rana Ejaz Ali Khan \\ The Islamia University of Bahawalpur \\ Khadija Malik Bari \\ Institute of Business Administration, Karachi, Pakistan \\ Muhammad Ali Raza \\ Institute of Business Administration, Karachi, Pakistan
}

Follow this and additional works at: https://ir.iba.edu.pk/businessreview

Part of the Economics Commons

\section{(c) (1)}

This work is licensed under a Creative Commons Attribution 4.0 International License.

\section{Recommended Citation}

Khan, R. E., Bari, K. M., \& Raza, M. A. (2019). Socioeconomic determinants of child mortality: Evidence from Pakistan Demographic and Health Survey. Business Review, 13(2), 34-50. Retrieved from https://doi.org/10.54784/1990-6587.1029

This article is brought to you by iRepository for open access under the Creative Commons Attribution 4.0 License and is available at https://ir.iba.edu.pk/businessreview/vol13/iss2/3. For more information, please contact irepository@iba.edu.pk. 


\title{
Socioeconomic determinants of child mortality: Evidence from Pakistan Demographic and Health Survey
}

\author{
Rana Ejaz Ali Khan - Khadija Malik \\ Bari · Muhammad Ali Raza
}

\begin{abstract}
This paper attempts to highlight socioeconomic determinants of child mortality in Pakistan. Binary logistic regression is applied to 7297 observations from the Pakistan Demographic and Health Survey 2012-13. The results reveal that probability of child mortality decreases with greater birth-interval, child's large size at birth, more family members, mother's education, mother's ownership of assets and mother's decision-making at the household level. Policy makers can work to improve mothers' characteristics such as fertility behavior, education, empowerment and decision-making at the household level, to reduce child mortality.
\end{abstract}

Keywords Child mortality · Fertility behavior - Women empowerment.

\section{Introduction}

Child mortality is the foremost indicator of population welfare. From the 20th century onwards, a declining trend in infant and child mortality has been observed. However, the reduction in child mortality varies among nations and regions. In Pakistan, the current under-5 mortality rate is 86 per 1,000 live births compared to 94 in 2007 and 117 in 1986. Not only the decline in child mortality is slow but the child mortality rate is still high.

Annually, about 50 percent of the global under-5 mortalities happen in only five nations. One of them is Pakistan, along with China, Congo, India and Nigeria. In Pakistan, more than 420,000 children (under-5 years) die every year. Within South Asia, the child mortality rate in Pakistan is ahead of Bangladesh,

Rana Ejaz Ali Khan

The Islamia University of Bahawalpur, Bahawalpur-Pakistan

Khadija Malik Bari

Institute of Business Administration, University Road, Karachi-Pakistan

E-mail: kbari@iba.edu.pk

Muhammad Ali Raza

Institute of Business Administration, University Road, Karachi-Pakistan 
India, Nepal and Bhutan that have child mortality rates of 41, 53, 40 and 36 per 1,000 live births respectively.

High child mortality is indicative of low levels of socioeconomic development (Anderson et al 2002). It has economic and social costs and countries lose a significant part of GDP due to child mortality (Bloom and Williamson 1998). In the social and demographic context, child mortality affects family structure and birth rate. It also increases fertility (Eckstein et al 1999).

Sustainable Development Goal 3 is to reduce under-5 mortality rate to at least as low as 25 per 1,000 live births by 2030 . How to achieve this goal is less widely agreed upon due to variations in cultural and socioeconomic factors of high child mortality among nations.

Factors contributing to child mortality may be classified into two categories based on the unit of analysis. These are factors influencing child mortality at the national level and factors influencing child mortality at the household level. Factors influencing child mortality at the national level include the availability of health-care facilities, medical experts, poverty, fiscal implications, public sector health policy, national literacy status, population welfare programs and fertility. Factors affecting child mortality at the household level are related to the behavior and capacity of households, such as socioeconomic status, cultural and social norms of the family, educational level of the parents, fertility preferences and women's socioeconomic autonomy.

This study attempts to identify socioeconomic determinants of child mortality at the household level. It also proposes a policy framework for bringing down child mortality in Pakistan.

\section{Methodology}

\subsection{Theoretical background}

There are a quite a few models concerning demand for human health, healthseeking behavior and health outcomes. Initially Grossman (1972) launched the concept that medical-care demand by individuals, households and communities is extracted from the demand for good health. This may be applicable to the outcomes of health like child's anthropometric measurements and probability of life. The determinants of child mortality under the Grossman (1972) model may be classified into child characteristics, mother's socio-demographic characteristics, household characteristics, regional characteristics and community characteristics.

Andersen and Newman (1973) cultivated the behavior model for health-care utilization that may also be associated with health outcomes like child mortality. It explains the theoretical structure demonstrating the factors responsible for health-care utilization. The predisposing factors comprising of precautionary measures for good health, e.g. vaccination, prenatal-care, postnatal-care and safe delivery; enabling factors comprising of capacity of the authority (individual, household or community) to seek health-care, e.g. wealth, socioeconomic and financial status, ownership of assets and provision of health insurance; and 
need factors comprising of symptoms of the disease, e.g. cough, diarrhea, low birth-weight and malnutrition may be adopted for child mortality.

Mosley and Chen (1984) suggested biological and medical proximate determinants of child mortality and classified them into five categories, i.e. maternal factors, environmental contamination, nutrient deficiency, injury and illness. Theoretically, entire social, cultural and economic distal determinants of child mortality operate under these proximate determinants. They may be categorized into individual, household and community variables (Mosley 1985). However, Pande (2003) converted this theoretical structure for child mortality into outcomes of child health measured by anthropometric measurements. To examine the socioeconomic determinants of child mortality the theoretical structure given by Mosley and Chen (1984) and Mosley (1985) has been adopted by this study.

\subsection{Selection and quantification of variables}

Under the Mosley and Chen (1984) and Mosley (1985) framework, the variables capturing the determinants of child mortality are identified from the Pakistan Demographic and Health Survey (PDHS) 2012-13. This framework is based on a set of intermediate variables (Hill 2003) which combines economic factors and relevant medical approach about causes of morbidity (Mosley and Chen 1984). Based on this framework, Schultz (1984) has recommended the health production function as an economic model, in which child mortality is the outcome of these intermediate variables. Hanmer et al (2003) noted that this model grasps the effects of socioeconomic factors on mortality. Hence a set of proximate determinants has been identified for this study.

Majority of the variables under analysis are taken from the survey and are self-explanatory. These variables are child's sex, birth-order, birth-size, preceding birth-interval, place of residence, household size, mother's education, use of tobacco by the mother and mother's working status. However, some of the variables have been constructed from the information given in the data. They are wealth index, woman's ownership of assets index and woman's decision-making index. $^{1}$

According to ?, household wealth index is one of the best measures of household welfare. Furthermore, they disclosed that the status of the household according to the index of ownership of assets remained at par with that of the expenditure approach (Filmer 1999). For the current analysis, wealth index created by PDHS has been utilized. The wealth index comprised of the components of household characteristics such as the provision of electricity, drinking water, sanitation facility, cooking fuel, and kind of roof material, wall material and

\footnotetext{
1 These are not the only variables affecting child mortality. A variety of other socioeconomic factors like access to electricity, water and sanitation, safe drinking water, housing condition, immunization of children and mother, age of the mother at first birth, medical maternity care, maternal and child nutrition, health-seeking behavior of mothers, physical work during pregnancy, place of delivery, breast-feeding, postnatal visits, etc. affect child mortality as well (Agha 2000; Ali 2001; Breiman et al 2004; WorldBank 2007; Ezeh et al 2015; Iram and Butt 2008; Khan and Awan 2017).
} 
floor material. It also includes the ownership of durable goods like wardrobe, table, chair or bench, watch or clock, radio, television, bicycle, sewing machine and telephone, and land ownership.

PDHS has divided the index into five quintiles. In the current analysis, the lowest to highest quintiles are included as continuous variables. The components of the wealth index justify the hypothetical relationship between wealth index and child mortality. For instance, poor material of the floor, unsafe drinking water and poor sanitation facility increases the probability of diarrhea in children. Similarly, the provision of radio and television in the households represents the enhanced health and nutrition information available to mothers. The presence of a vehicle in the household explains the enhanced mobility of the household members in case of an urgent need for medical treatment. Poor wall and floor material, non-availability of cooking fuel and non-electric source of lighting is associated with the danger of respiratory diseases (Rutstein et al 2000). These elements translate into risk for a child's life.

The ownership of assets by the households, particularly high-value assets has many implications. It provides financial protection to the family members against income or employment loss. The ownership of assets by women endows economic empowerment and provides back up in case of marital dissolution or abandonment. The PDHS provides information on woman's ownership (alone, jointly, and alone and jointly) of two high value assets, i.e. land and or house.

To capture the effect of ownership of assets by women on child mortality, the ownership of assets by married women aged 15-49 years has been transformed into an index through the Principal Component Analysis (PCA). In the first stage values are assigned to different categories of ownership of house and land. The woman who does not own assets is assigned the value zero. Similarly, the woman who jointly owns assets is assigned the value 1 ; the woman who alone and jointly owns the assets is assigned the value 2 ; and the woman who alone owns the assets is assigned the value 3 . In the second stage, index of assets is created using PCA.

Literature holds quite a few different definitions of empowerment. It is a blend of agency, resources and achievements (Kabeer 1999). The terms empowerment and autonomy are repeatedly used interchangeably but some studies differentiate the two by defining autonomy as the freedom to do certain things and empowerment as resisting denial of one's rights (Dixon-Mueller 1998). Empowerment is also defined as the process of being able to take charge of one's own life (Malhotra and Mather 1997). The ability of a woman to make decisions that affect her personal preferences represents her empowerment. It is an important contributor to overall woman development.

To assess married women's decision making, the PDHS collected information on women participation in four types of decisions, about their own health care, making major household purchases, visits to family or relatives, and decision about husband's earning. The four questions were asked as: person who usually decides on respondent's health care?, person who usually decides on large household purchases?, person who usually decides on visits to family or relatives? and person who usually decides what to do with the money that the husband earns? The responses were recorded as someone else, mainly husband, 
wife and husband jointly, and mainly wife.

To construct the woman decision-making index, the four responses were first coded as: 0 if decision is taken by someone else, 1 if it is taken by the husband, 2 if decision is taken by the wife and husband jointly, and 3 if it is taken mainly by the wife. Then the index is constructed using PCA.

\subsection{Data}

The PDHS 2012-13 is the third survey of the series. It is a nationally representative survey covering the entire population using a sample of 14,000 households (6,944 urban and 7,056 rural households). The PDHS is designed to collect data about demographic, maternal and child health indicators with the purpose of providing reliable and updated information for policymakers and program managers. The micro-data of PDHS 2012-13 is utilized for this analysis.

Table 1: Operational definition of variables

\begin{tabular}{|c|c|}
\hline Variables & Definitions \\
\hline \multicolumn{2}{|l|}{ Dependent variable } \\
\hline $\begin{array}{l}\text { CMORT (Child mortality) } \\
\text { Explanatory variables }\end{array}$ & 1 if child is not alive, 0 otherwise \\
\hline SEX (Sex of child) & 1 if child is female, 0 otherwise \\
\hline BORD (Child's birth order) & 1 if child's birth order $>2,0$ for $\leq 2$ \\
\hline BINT (Preceding birth-interval) & $\begin{array}{l}1 \text { if child's preceding birth interval }>24 \text { months, } 0 \text { for } \leq 24 \\
\text { months }\end{array}$ \\
\hline SIZE (Child's size at birth) & 0 for small birth size, 1 for average, 2 for large \\
\hline POR (Place of residence) & 1 for rural, 0 for urban \\
\hline WEALTH (Wealth index) & $\begin{array}{l}0 \text { for poorest, } 1 \text { for poorer, } 2 \text { for middle, } 3 \text { for richer, } 4 \text { for } \\
\text { richest }\end{array}$ \\
\hline HHS (Household size) & 1 if household size $>4,0$ for $\leq 4$ \\
\hline SOD (Skilled attendance of delivery) & $\begin{array}{l}1 \text { if delivery is attended by doctor, nurse, midwife or LHV, } 0 \\
\text { otherwise }\end{array}$ \\
\hline MEDU (Mother's education) & $\begin{array}{l}0 \text { for no education, } 1 \text { for primary, } 2 \text { for middle, } 3 \text { for sec- } \\
\text { ondary, } 4 \text { for higher }\end{array}$ \\
\hline TOBCO (Use of tobacco by mother) & 1 if mother uses tobacco, 0 otherwise \\
\hline MWS (Mother's working status) & $\begin{array}{l}0 \text { if mother is not working, } 1 \text { if mother is working and has no } \\
\text { education, } 2 \text { if mother is working and has primary, middle or } \\
\text { secondary education, } 3 \text { if mother is working and has higher } \\
\text { level of education }\end{array}$ \\
\hline MOA (Mother's ownership of asset) & Continuous, mother's ownership of assets index \\
\hline MDM (Mother's decision-making) & Continuous, mother's decision-making index \\
\hline
\end{tabular}

\subsection{Model specifications}

Binary logistic regression has been employed to ascertain the determinants of under-5 child mortality in Pakistan. The 7297 observations are extracted from 
the micro-data set of PDHS. The estimation equation is given as:

$$
\begin{aligned}
C M O R T= & f\left(S E X_{i j}, B^{\prime} O R D_{i j}, B I N T_{i j}, S I Z E_{i j}, P O R_{i j}, W E A L T H_{i j}, H H S_{i j}\right. \\
& \left.S O D_{i j}, M E D U_{i j}, T O B C O_{i j}, M W S_{i j}, M O A_{i j}, M D M_{i j}\right)
\end{aligned}
$$

The operational definitions of the variables are given in table 1 .

\section{Results and discussion}

\subsection{Econometric estimates}

The functional relationship between co-variates and child mortality is estimated using binary logistic regression. The average estimates are shown in table 2 and binary logistic regression results are expressed in table 3 . The percentage estimates reveal some distinguishing features.

(1) Child mortality is higher for female as compared to male children.

(2) Children with more than two birth-orders have higher child mortality.

(3) Children with lesser than or equal to 24 months preceding birth-interval have higher child mortality.

(4) Children of smaller birth size have higher child mortality than average or large birth-size children.

(5) Rural households have higher child mortality than urban households.

(6) Households in the lowest wealth quintile have higher child mortality than the households in the upper most four quintiles of the wealth index (poorer, middle, richer and richest). Child mortality decreases by incremental change of the household from the poorest to the richest household.

(7) Households with size of less than or equal to four members have higher child mortality as compared to their counterparts having more than four members.

(8) Mothers who receive unskilled attendance of delivery have higher child mortality.

(9) Child mortality is higher for illiterate mothers (no education) as compared to literate mothers with primary, middle, secondary and higher level of education. Child mortality decreases as the level of education of the mother increases from primary to higher.

(10) Mothers who smoke during pregnancy suffer higher child mortality than those who do not smoke.

(11) Working mothers with no education suffer higher child mortality than nonworking mothers. However, working mothers with higher education have lower child mortality than non-working mothers. Working mothers having up to secondary education also have higher child mortality as compared to non-working mothers.

(12) Women having assets below the median level of ownership of assets index have higher child mortality as compared to their counterparts who have assets above the median of ownership of assets index. 
Table 2: Percentage estimates of child mortality in Pakistan

\begin{tabular}{|c|c|c|}
\hline Background characteristics & Under-5 Mortality (\%) & Number of children \\
\hline \multicolumn{3}{|l|}{ Sex of child } \\
\hline Male & 7.0 & 3730 \\
\hline Female & 7.9 & 3567 \\
\hline \multicolumn{3}{|l|}{ Child's birth-order } \\
\hline$\leq 2$ & 4.7 & 1610 \\
\hline$>2$ & 8.2 & 5687 \\
\hline \multicolumn{3}{|l|}{ Preceding birth-interval } \\
\hline$\leq 24$ Months & 11.8 & 2679 \\
\hline$>24$ Months & 4.9 & 4618 \\
\hline \multicolumn{3}{|l|}{ Child's size at birth } \\
\hline Small & 12.0 & 1462 \\
\hline Average & 6.4 & 5369 \\
\hline Large & 5.8 & 466 \\
\hline \multicolumn{3}{|l|}{ Place of residence } \\
\hline Urban & 6.1 & 2974 \\
\hline Rural & 8.4 & 4323 \\
\hline \multicolumn{3}{|l|}{ Wealth index } \\
\hline Poorest & 9.7 & 2081 \\
\hline Poorer & 8.0 & 1544 \\
\hline Middle & 6.7 & 1355 \\
\hline Richer & 6.1 & 1224 \\
\hline Richest & 4.7 & 1093 \\
\hline \multicolumn{3}{|l|}{ Household size } \\
\hline$\leq 4$ & 13.0 & 563 \\
\hline$>4$ & 7.0 & 6734 \\
\hline \multicolumn{3}{|l|}{ Skilled attendance of delivery } \\
\hline No & 8.1 & 3883 \\
\hline Yes & 6.6 & 3414 \\
\hline \multicolumn{3}{|l|}{ Mother's education } \\
\hline No education & 8.6 & 4662 \\
\hline Primary & 7.4 & 964 \\
\hline Middle & 5.0 & 443 \\
\hline Secondary & 4.6 & 613 \\
\hline Higher & 3.3 & 615 \\
\hline \multicolumn{3}{|l|}{ Use of tobacco by mother } \\
\hline No & 7.1 & 6655 \\
\hline Yes & 10.7 & 642 \\
\hline \multicolumn{3}{|l|}{ Mother's working status } \\
\hline No & 6.7 & 5668 \\
\hline Yes (No education) & 11.2 & 1174 \\
\hline $\begin{array}{l}\text { Yes (Education less than and equal to } \\
\text { secondary level) }\end{array}$ & 10.6 & 303 \\
\hline Yes (Higher education) & 1.3 & 152 \\
\hline \multicolumn{3}{|l|}{ Mother's ownership of assets index } \\
\hline$\leq$ Median & 7.9 & 6153 \\
\hline$>$ Median & 4.8 & 1144 \\
\hline \multicolumn{3}{|l|}{ Mother's decision-making index } \\
\hline$\leq$ Median & 8.1 & 3627 \\
\hline$>$ Median & 6.8 & 3670 \\
\hline Total & 7.4 & 7297 \\
\hline
\end{tabular}


(13) Similarly women with decision-making below the median level of the decisionmaking index have higher child mortality as compared to women with decisionmaking above the median level of the decision-making index.

Table 3: Results of binary logistic regression for child mortality in Pakistan

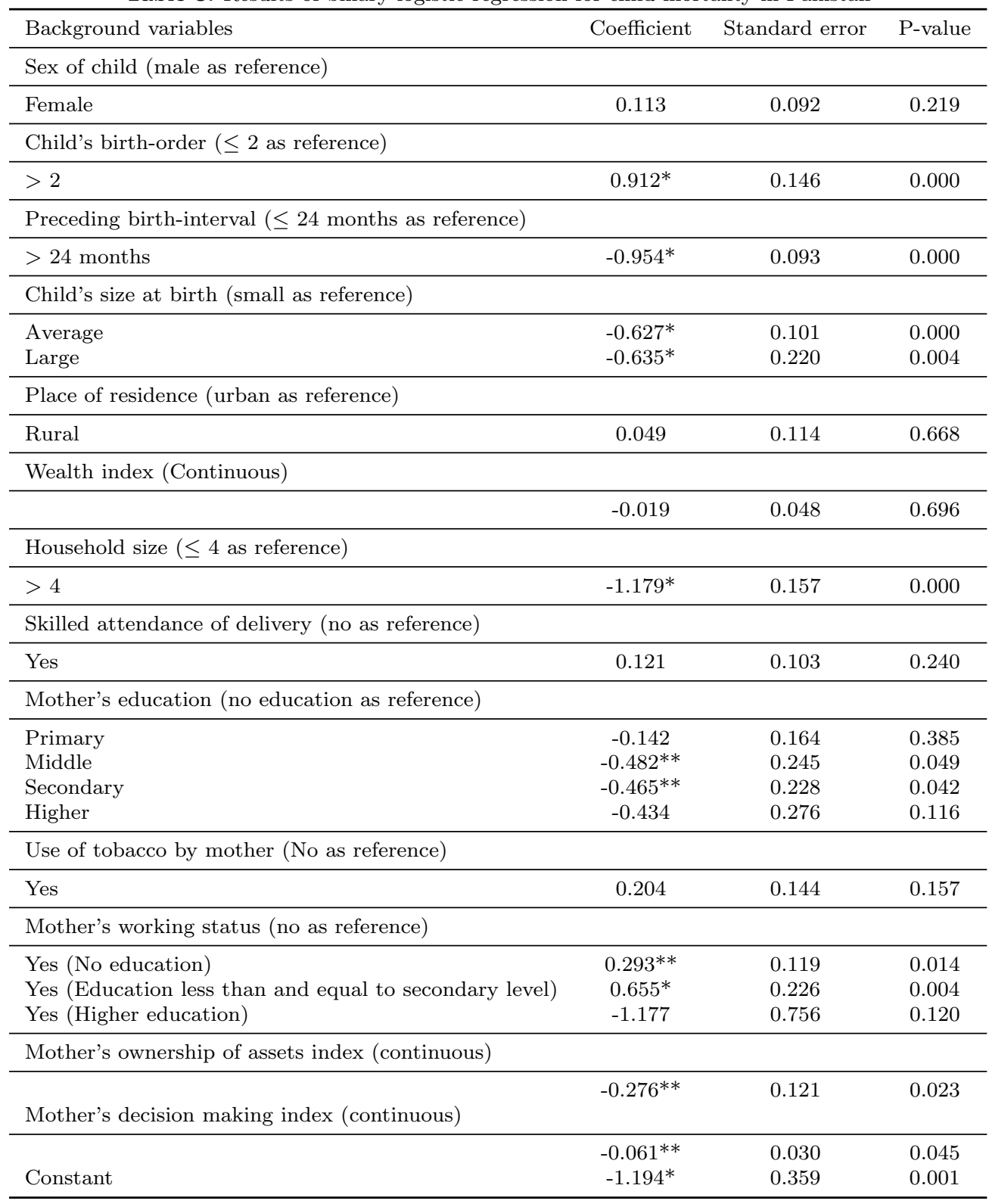

*, **,*** Significant at 1,5 and 10 percent level respectively 


\subsection{Discussion}

Majority of the results are theoretically supported.

\subsubsection{Child's sex}

The child's sex may affect the probability of child mortality positively or negatively, even though it may remain neutral in affecting child mortality. The direction of the impact depends upon the socioeconomic and cultural factors in the country.

Econometric estimates have shown no significant impact of child's sex on child mortality. However, in the percentage estimates it is clear that child mortality is higher in females as compared to males. Rutstein (2008) explained that female children have higher morbidity in most cultures of developing economies because families here prioritize the male gender for their offspring.

\subsubsection{Child's birth-order and interval}

The health, nutritional status and growth of the child during the first five years of his life are associated with fertility and family planning related initiatives of the mother. These include the number of children born alternatively, the birthorder of child and the interval between the births. They consequently affect the child's likelihood of survival (Claeson et al 2000).

The estimates of the current study revealed that children born after two births have higher probability of mortality during their first five years of life. The percentage estimates explain that children born after the birth-order of two have 1.74 times higher mortality than their counterparts born at first or second birth-order. This finding is also supported by literature (Ezeh et al 2015; Khan and Awan 2017).

The results have also shown that birth-interval has negative influence on child mortality (Sathar 1987; Kozuki and Walker 2013; Khan and Awan 2017). Children born with shorter birth-interval have less probability of survival as compared to children born after more than 24 months birth-interval. This is also supported by the average estimates, i.e. the mortality in children born with shorter birth-interval is 11.8 percent and that in children with longer birthinterval is 4.9 percent. The child's birth-order and birth-interval are basically related to fertility and family planning. They affect child mortality in a way that signifies the need to focus on these two areas not only to decrease the number of children but the birth spacing as well.

\subsubsection{Child's size at birth}

The child's small size at birth or low birth-weight presents a greater probability of contracting diseases, malnutrition and slow physical and mental growth during childhood. The birth-weight of the child in the preceding five years of the PDHS was recorded from the birth card of the child or the recall of the 
mother about the birth size of child. It was categorized into very small, smaller than average, average, larger than average, and very large as disclosed by the mother. Although such estimates are subjective but may be used as a proxy for birth-weight particularly in the case of Pakistan where majority of the births take place at homes and weight of the child is never measured (NIPS and ICFInternational 2013).

In 2006-07, according to PDHS only one out of ten newborns were weighed at birth and among them almost one quarter were found under-weight (NIPS and MacroInternational 2008). For these reasons, birth size of the child has been included in the model instead of birth-weight (Nisar and Dibley 2014). The categories of very small and smaller than average have been merged into small, and larger than average and very large into large. This makes the variable of birth size a categorical variable having three categories of small, average and large.

Literature holds that low birth-weight children and small birth size children suffer from a greater risk of mortality. The estimates of the current study have shown that children with average and large size at birth are less probable to die during the first five years of life (Nisar and Dibley 2014). This is supported by the results of percentage estimates of child mortality, that is mortality in children with small, average and large size at birth is $12,6.4$ and 5.8 percent respectively.

\subsubsection{Place of residence}

Theoretically it is hypothesized that child mortality is more prevalent in rural households than urban ones. This may be due to higher wealth and socioeconomic status of the urban households which enable the parents to avail better health facilities for their children and consume hygienic nutrition.

The rural-urban disparity persists in developing economies like Pakistan in a number of socioeconomic aspects like awareness, media accessibility and education. In this analysis the household's urban or rural residence has been included in the estimation as a binary variable to see whether the probability of child mortality differs for urban and rural households. No significant impact has emerged from econometric estimates showing that place of residence of the household has no effect on probability of child mortality. However, average estimates revealed that child mortality is 8.4 and 6.1 percent in rural and urban households respectively which indicates rural-urban disparity in child mortality in Pakistan.

\subsubsection{Wealth index}

The socioeconomic status of the household has been captured by the wealth index. It has been frequently utilized in literature for household health analysis due to lack of alignment among incomes of the households, health-care utilization (particularly child and mother) and outcomes of health-care services (Filmer and Pritchett 2001; Rutstein et al 2000). It was speculated that socioeconomic status proxied by the wealth index decreases probability of child mortality. It is strange to note that econometric results have shown insignificant 
effect of wealth index on child mortality. The average estimates depict lower ratio of child mortality in rich households than the poor ones. Child mortality in poorest, poorer, middle, richer and richest households is 9.7, 8.0, 6.7, 6.1 and 4.7 percent respectively.

\subsubsection{Household size}

Child mortality may theoretically be influenced by household size positively or negatively through the channels of child health-care and nutrition. The negative impact of household size, i.e. larger household size decreases child mortality, can be attributed to the combined family system. The household head in this system collects the earnings of all members of the household and spends on household welfare. In this way the pooled income increases child welfare in the form of health-care and nutrition. This pooled income may be utilized for children's food, medical-care, nutrition and mother's care during pregnancy.

Alternatively, a large household size comprising of many household members may dilute the per-capita income of the household and the per-capita resources available to the members of the household. This may reduce child welfare. The consequent two options of this phenomenon depends on the ratio of employed and working-age members in the household. The household may comprise of a large number of employed adults or conversely the dependents like children, oldage members and women. This influences the direction of the effect of household size.

The results have shown that larger households have lower probability of child mortality, that is households with more than four members face lesser likelihood of child mortality than the households with less than or equal to four members. It is corroborated by the average estimates that child mortality is 13 percent in households with lesser or equal to four members and 7 percent in households with more than than four members. This is empirically supported by the other studies, for instance Khan and Raza (2014) concluded that in Bangladesh larger households produce comparatively lesser number of malnourished children (Mozumder et al 2000).

\subsubsection{Skilled attendance of delivery}

Health-care services for mothers in the form of prenatal-care, skilled birth attendance, institutional place of delivery and postnatal-care contribute to the likelihood of child and mother survival (WHO 1991). Child and maternal mortality particularly is determined by the quality of obstetric-care provided during natal and postnatal check-ups. These check-ups affect the morbidity, food intake by the child, growth and consequently the likelihood of life.

Mothers who deliver at home do so without professional attendance whereas those who deliver at hospitals avail the facility of skilled birth attendance. In the survey, the information about the utilization of services of skilled birth professionals during pregnancy was acquired from mothers who had delivered a live child during the five preceding years. Multiple responses were received and if more than one individual had assisted, only the most qualified attendant was 
considered. The current study converted this variable into binary form such that the value 1 is assigned, if the assistance during birth was provided by a doctor, nurse, midwife or lady health visitor, and otherwise zero.

Conceptually maternal health-care in the form of prenatal-care, natal-care and postnatal-care serves as a shield against morbidity of mother and child. It also brings down malnutrition in children. So prenatal visits, quality of prenatalcare and skilled birth attendance are likely to decrease child mortality.

In the current analysis one component of maternal-care, i.e. skilled birth attendance has been included in the model. This component is seemed sufficient to cover most of the maternal health-care, based on the assumption that skilled birth attendance is consequent to prenatal visits to quality source of prenatal-care, i.e. a doctor. ${ }^{2}$ The results show no significant impact of skilled birth attendance on the probability of child mortality in Pakistan. The average estimates show that the child mortality rate is 8.1 percent for mothers who have not availed skilled birth attendance against 6.6 percent for those who have availed skilled birth attendance.

\subsubsection{Mother's education and working status}

The mother's education and employment are assumed to be key determinants of child welfare in the form of health, education and nutrition. Mother's education as a categorical variable has been added in the estimation. It comprises of five categories, i.e. no schooling, primary, middle and secondary schooling, and college or higher education. The first category, i.e. no schooling serves as the reference category.

It is hypothesized that mother's education reduces the likelihood of child mortality. The results reveal that probability of child mortality decreases by the middle and secondary education of the mother (Ali 2001; Breiman et al 2004; Iram and Butt 2008; Khan and Awan 2017). Primary education has a statistically insignificant effect on probability of child mortality. ${ }^{3}$ College or higher education has also shown statistically insignificant effect on child mortality.

These results have very important policy implications, i.e. primary education is not sufficient for women to contribute to reduce the risk of child mortality. Therefore the education policy should focus on at least ten years of education. The explanation of the insignificant effect of higher education on child mortality may be that higher education enrollment for females is very scarce in Pakistan.

It is generally perceived and empirically evidenced that woman's education and working status enhance the household health particularly of women and children (Agha 2000; Claeson et al 2000; Ali 2001; Aslam and Kingdon 2012). It may be assumed that not all levels of education and all kinds of work increase the household welfare, as it has been seen that education of five years cannot

\footnotetext{
2 Although some of the cases may be such that the skilled birth attendant is availed when the delivery case becomes complex and the traditional healer refuses to deal with it.

3 Ali (2001) has found primary level of education as the threshold level of education for women to enable them to protect their children's life. He combined the women having no education (illiterate) and up to primary education to observe education's effect on child mortality in Pakistan.
} 
decrease the probability of child mortality because this level of education is not functional education.

From the policy perspective, information about the level of education that makes a woman functional is very important. Therefore in the policy framework the functional level of education that is at least ten years should be recommended. Similarly, all kinds of work by women cannot contribute in decreasing a child's risk of mortality. Informal sector employment of woman cannot decrease the risk of child mortality, in fact it may even increase child mortality. Informally employed women keep the infant with them during work and often do not get sufficient time for breastfeeding or providing supplementary food for the child. It also becomes difficult for them to maintain daily timings of supplementary food. These factors keep the child malnourished and unhealthy which may increase the probability of child mortality.

To detangle the puzzle, that whether all kinds of work by women results in decreased likelihood of child mortality, an interacting variable of working status and educational level of woman has been created. Working women with no education or education up to secondary level are assumed to belong to informal sector labor market. If the informal sector employment of women does not contribute in decreasing child mortality then recommendation for labor policy should be to increase the formal sector employment of women or to cover all kinds of women employment under the formal sector network.

This study included the working status of the mother as an interacting variable with her education. By combining the education and working status four dummies were created. First and the reference category, if the mother was not working; second category, if the mother was working and had no schooling; third category, if mother was working and had education less than or equal to secondary level; and the last category, if mother was working and had education up to higher level. The purpose of this interacting variable is to see the effect of an employed mother having different levels of education on child mortality.

The results explain that employed mothers with no-education and employed mothers with maximum ten years of education increase the probability of child mortality in Pakistan. However, employed mothers with higher education negatively affect probability of child mortality although the results are statistically insignificant. The explanation may be that the working women with no education and up to secondary level of education are assumed to belong to the informal sector labor market. The informal sector employed women are usually under-paid, seasonally employed, casual workers, daily wagers, self-employed and marginally employed women. They do not have enough income to use health-care facilities and to provide adequate nutrition to their children. Even during pregnancy they do not have enough time to take rest due to long working hours and do not enjoy weekly holidays. They work in hard working environments and under harsh weather conditions. In working days they cannot take prenatal-care and subsequently child-care adequately. All these factors collectively enhance child mortality among these women.

This is supported by Sathar (1987) and Ali (2001) for Pakistan, that women employment increases child mortality. Ali (2001) explained that women are frequently employed in their family businesses or cottage industries as helpers and 
they do not have sufficient income to rear and nourish their children in a good way. Sathar (1987) explained that child mortality is higher in women working in low paid jobs. Nisar and Dibley (2014) concluded that mother's work outside the home may increase neonatal mortality due to insufficient health-care, care regarding feeding, cleaning and medication.

The general perception that woman's working status decreases child mortality is negated by these results. The results explain that the informally employed working women increase the probability of child mortality instead of decreasing it. It is recommended to implement the minimum wage and labor policy concerns for informal sector working women. Social security benefits for the health-care of infants and children should be provided to such women.

The insignificant effect of working women with higher education on child mortality explains the fact that in the survey the ratio of highly educated women is very small. The result is partially corroborated by the previous variable of woman's education where higher education has no significant effect on child mortality.

\subsubsection{Use of tobacco by the mother}

Smoking of tobacco by the mother causes a wide variety of diseases to herself and the child. Even the secondhand smoke adversely affects child health and aggravates childhood diseases particularly respiratory illnesses. To enquire the use of tobacco by women, the PDHS asked various questions about the use of tobacco and its products.

The study included in the analysis a binary variable assuming the value one if mother uses any kind of tobacco (cigarettes, pipe, biri, any other type of tobacco), otherwise, zero. The results have shown statistically insignificant effect of mother's smoking on child mortality. The possible explanation may be that the female tobacco smokers are in a thin ratio. However, the average estimates of the data show that the mothers with tobacco smoking suffer 10.7 percent child mortality against 7.1 percent of child mortality suffered by mothers who do not smoke tobacco.

\subsubsection{Ownership of assets by the mother}

To see the impact of ownership of assets by the mother on child mortality an index of the ownership of assets was constructed and values of the index were included as a continuous variable in the estimation. The logistic regression results have revealed that the likelihood of child mortality decreases with an increase in ownership of assets by the mother (Agha 2000). The result is supported by the percentage estimates where the mothers' who have assets above the median of the index of ownership of assets suffer 4.8 percent child mortality against the 7.9 percent child mortality suffered by mothers having assets below or equal to the median of the index.

Ownership of assets by the mother enhances her socioeconomic status within the household, increases the mobility of the mother, her decision-making within the household and economic support to implement the decisions regarding child 
health-care, food and nutrition. Mother is the main care-taker of the child, so ownership of assets by the woman makes her more autonomous for the care of the child.

\subsubsection{Mother's decision-making}

Woman empowerment, autonomy and decision-making at the household level have been discussed in literature frequently for the welfare of children and women in developing economies. Different indicators have been used for these alternative terms. The impact of these indictors on health outcomes and healthcare behavior are still not robust. Possibly it is due to different socioeconomic conditions of the study areas and use of varying indicators.

In the current analysis, the mother's decision-making has been measured through an index that is included in the estimation as a continuous variable. The regression results expressed that women empowerment in the household expressed by the mother's decision-making index decreases the probability of child mortality. It is also supported by the percentage estimates where women having decision-making above the median of the decision-making index suffer 6.8 percent child mortality against 8.1 percent child mortality suffered by women having decision-making below or equal to the median value of the women empowerment index. The explanation may be that through decision-making the mother enhances the chances of child survival by providing proper health-care, nutrition and food.

\section{Conclusion and Policy Recommendations}

This study focused on examining the socioeconomic determinants of child mortality in Pakistan. The results demonstrated no evidence of gender disparity in child mortality. This explains that the health-behavior of parents towards their male and female offspring is unbiased.

The estimation has proved that higher birth-order alternatively, larger number of children and low birth-spacing are the responsible factors for high child mortality in the country. The fertility behavior of the households through family planning programs may be the feasible targets to reduce child mortality.

It is inferred from the results that low birth-weight enhances child mortality, so public policy regarding maternal health through targeting the mothers for their nutrition, prenatal-care and food supplementation during pregnancy can contribute to lower child mortality.

It is concluded that child mortality can be reduced significantly by improving the mother's education. Women's education may have spillover effects on fertility and maternal health-care behavior that can bring down child mortality. Regarding the influence of mother's education on child mortality, there emerged an important aspect of female education, that is mother's education up to five years has no significant effect on child mortality. It signifies the importance of ten years of compulsory education for children.

A foremost outcome of the study is that employment status of the women in 
the informal sector increases child mortality. It negates the notion that woman's working status increases household resources, pool the household income and boosts the confidence and mobility of woman and ultimately decreases child mortality. The results explain that the women employed in the informal sector do not have sufficient wages and lack employment security, social benefits and fixed working hours. They work in harsh weather conditions and unhygienic work places which affect not only their own health but the children's health as well. So instead of increasing the general employment of women, it is neccesary to increase the formal sector employment of women and ensure implementation of the labor laws.

Majority of the determinants of child mortality are related to mothers/women. It is concluded that women's ownership of assets and decision-making power of women at the household level alternatively woman empowerment at the household level decreases child mortality. Ministry of Women Development in Pakistan should focus on different aspects of women empowerment, women employment and health. Similarly NGOs and international organizations working for women are proposed to play their role in women development.

\section{References}

Agha S (2000) The determinants of infant mortality in pakistan. Social Science and Medicine $51: 199-208$

Ali SM (2001) Poverty and child mortality in pakistan. NIMAP Technical Paper Series No.6:Pakistan Institute of Development Economics

Andersen R, Newman JF (1973) Societal and individual determinants of medical care utilization in the united states. Milbank Memorial Fund Quarterly: Health and Society 51:95-124

Anderson BA, Romani JH, Phillips HE, Van Zyl JA (2002) Environment, access to health care, and other factors affecting infant and child survival among the african and coloured populations of south africa, 1989-94. Population and Environment 23(4):349-364

Aslam M, Kingdon GG (2012) Parental education and child healthunderstanding the pathways of impact in pakistan. World Development 40(10):2014-2032

Bloom DE, Williamson JG (1998) Demographic transitions and economic miracles in emerging asia. The World Bank Economic Review 12(3):419-455

Breiman RF, Streatfield PK, Phelan M, Shifa N, Rashid M, Yunus M (2004) Effect of infant immunisation on childhood mortality in rural bangladesh: analysis of health and demographic surveillance data. The Lancet 364(9452):2204-2211

Claeson M, Bos ER, Mawji T, Pathmanathan I (2000) Reducing child mortality in india in the new millennium. Bulletin of the World Health Organization 78:1192-1199

Dixon-Mueller R (1998) Famale empowerment and demographic process: Moving beyond cairo policy and research paper no. 13. Paris: International Union For The Scientific Study of population (IUSSP)

Eckstein Z, Mira P, Wolpin KI (1999) A quantitative analysis of swedish fertility dynamics: 1751-1990. Review of Economic Dynamics 2(1):137-165

Ezeh OK, Agho KE, Dibley MJ, Hall JJ, Page AN (2015) Risk factors for postneonatal, infant, child and under-5 mortality in nigeria: a pooled cross-sectional analysis. BMJ open 5(3):006,779

Filmer D (1999) The impact of public spending on health: Does money matter? Social Sciences and Medicine 49:1309-23

Filmer D, Pritchett L (2001) Estimating wealth effects without expenditure data or tears: An application to education and enrolment in states of india, demography 38(1):115-32

Grossman M (1972) On the concept of health capital and the demand for health. Journal of Political Economy 80(2):223-255

Business Review: (2018) 13(2):34-50 
R. Khan et al

Hanmer L, Lensink R, White H (2003) Infant and child mortality in developing countries: analysing the data for robust determinants. The Journal of Development Studies 40(1):101-118

Hill K (2003) Frameworks for studying the determinants of child survival. Bulletin of the World Health Organization 81:138-139

Iram U, Butt MS (2008) Socioeconomic determinants of child mortality in pakistan: Evidence from sequential probit model. International Journal of Social Economics 35(1/2):63-76

Kabeer N (1999) Resources, agency, achievements: Reflections on the measurement of women's empowerment. Development and change 30(3):435-464

Khan JR, Awan N (2017) A comprehensive analysis on child mortality and its determinants in bangladesh using frailty models. Archives of Public Health 75(1):58

Khan REA, Raza MA (2014) Nutritional status of children in bangladesh: measuring composite index of anthropometric failure (ciaf) and its determinants. Pakistan Journal of Commerce and Social Sciences 8(1):11-23

Kozuki N, Walker N (2013) Exploring the association between short/long preceding birth intervals and child mortality: using reference birth interval children of the same mother as comparison. BMC public health 13(3):S6

Malhotra A, Mather M (1997) Do schooling and work empower women in developing countries? gender and domestic decisions in sri lanka 12(4):599-630

Mosley WH (1985) Biological and socioeconomic determinants of child survival: A proximate determinants framework integrating fertility and mortality variables.

Mosley WH, Chen LC (1984) An analytical framework for the study of child survival in developing countries. Population and Development Review 10:25-45

Mozumder AB, Barket EK, Kane TT, Levin A, Ahmed S (2000) The effect of birth interval on malnutrition in bangladesh: Infants and young children. Journal of Biosocial Sciences $32: 289-300$

NIPS, ICFInternational (2013) Pakistan demographic and health survey 2012-13. National Institute of Population Studies (NIPS) and ICF International

NIPS, MacroInternational (2008) Pakistan demographic and health survey 2006-07. National Institute of Population Studies (NIPS) and Macro International Inc.

Nisar YB, Dibley MJ (2014) Determinants of neonatal mortality in pakistan: secondary analysis of pakistan demographic and health survey 2006-07. BMC Public Health 14(1):663

Pande RP (2003) Selective gender differences in childhood nutrition and immunization in rural india: the role of siblings. Demography 40(3):395-418

Rutstein S, Johnson K, Gwatkin D (2000) Poverty, health inequality, and its health and demographic effects. In: Annual Meeting of the Population Association of America, Los Angeles, California

Rutstein SO (2008) Further evidence of the effects of preceding birth intervals on neonatal infant and under-five-years mortality and nutritional status in developing countries: Evidence from the demographic and health surveys. Calverton: Macro International Inc

Sathar ZA (1987) Seeking explanations for high levels of infant mortality in pakistan. The Pakistan Development Review 26(1):55-70

Schultz TP (1984) Studying the impact of household economic and community variables on child mortality. Population and Development Review 10:215-235

WHO (1991) Maternal mortality: A global fact book. Geneva

WorldBank (2007) India: Achieving the mdg in india's poor states: Reducing child mortality in orissa. Human Report No 39855-IN 